\title{
Study of students' mental images effect on learning chemistry
}

\author{
Rasol Abdullah Mirzaie ${ }^{1, *} \quad$ Masoumeh Shahmohammadi $^{2} \quad$ Amrollah Kouhi $^{2}$ \\ ${ }^{1}$ Dep. of chemistry -Faculty of science - Shahid Rajaee Teacher Training University- P.O.Box 167855-163 \\ Tehran, Iran \\ ${ }^{2}$ Masters student in chemical education, faculty of science, - Shahid Rajaee Teacher Training University P.O. Box \\ 167855-163, Tehran, Iran
}

\begin{abstract}
It is clear that use of images has effect on teaching the chemistry concepts. In classrooms, some examples which are used for simplifying and understanding the material better are in macroscopic dimension and students do not understand particles such as atoms, molecules and ions well. In order to help them understand these concepts in macroscopic dimension, illustration is used. In illustration, students can reflect different concepts of chemistry which have learnt during teaching. One of the illustration methods is to use painting art, as one can determine the extent to which they have understood from chemistry concepts and relationship among different areas of the sciences, society and technology by studying paintings of these students. The Aim of this research is to determine through their paintings whether students have understood the taught concepts in chemistry of the first grade of high school in IRAN or not. These chemistry subjects include water, atmosphere, minerals and fuel. After teaching the above topics, the students were asked to select a subject at their will and paint about it. This research has been performed in two separate cities in IRAN but it has been implemented in equal age groups and it was specified that different places of residence had effects on selection of painting subject. Our experience showed that use of this method led to deep learning in the students and provided the opportunity for them to express their beliefs in scientific concepts in their own way and language. On the other hand, teacher performs a kind of continual evaluation in this way and understands students' misconceptions and tries to remove these errors before beginning new subject. This method is interesting for students so that most of them mentioned that painting the chemistry was new and interesting experience.
\end{abstract}

Key words: Pictography, misconception, chemistry education, paintings

\section{Introduction}

In chemistry, visualization is extremely important; we deal with atoms and molecules which cannot be seen with the naked eye, we can only visualize them. Over the centuries, different models were produced to help scientists and the public visualize of invisible. In the past few years, when we talk about chemical visualization, we typically mean computer models. Although this type of visualization is extremely important, we must remember that different people visualize with different models -- just as we accept the realization that different people learn in different ways (Multiple Intelligences). One of the main global problems that still exists in attracting students to study chemistry is that many teachers still do not take into account the different styles of learning which different students have, such as the "Multiple Intelligences," by Howard Gardner of Harvard University. Lately, "visualization" has become a buzzword, in both science and education. However, what is typically meant by "visualization" is a computer image, which is all-too-often produced by the instructor. There is no better way of learning than by "doing it by yourself." word "visualize" is defined as "To form a mental image or vision of; picture in the mind"(Zafra M. Lerman,2001).

The learners, when get familiar with chemistry as an independent course, for firs time; they are ready to receive basic view points and new feeling about this course. Therefore, using 
initiative methods in chemical education can help them learn this course and make appropriate relation between chemistry, society and technology.

In pictography, students can reflect different chemical concepts that they understand from teaching. They use their intelligence and imagination to express chemical learned concepts. Made pictures by students indicate something that they haven't learned well, hidden misconception and their understandings of chemical concepts.

\subsection{Research History}

In 1983, Heilbronner and Wyss asked Swiss pupils (11 to 15 years) to paint their images of chemistry. After collecting 151 paintings, the researchers were surprised at the artistic merit of the paintings, but at the same time they were deeply affected by the choice of motifs. Critical and disapproving attitudes towards chemistry were shown in $66 \%$ of the paintings. The paintings dealt with environmental pollution, threats to the individual by chemical industry and with animal experiments. Fantastic laboratories as "Frankenstein" and similar science-fiction scenes were shown by $33 \%$ of the paintings (Claus Hilbing and Hans-Dieter, 2000).

In 1998, the same research was performed in German schools, teaching chemistry effect on student's insight into chemistry has studied. In this study, the students were separated in two groups. One of groups after teaching chemistry and another group before any education in the field of chemistry has been studied. Two types of questions had been designed for evaluation of student's general chemistry insight in different groups. Open- ended and closed questions were used for first and second group respectively (Wenck, H., Müller-Harbich, G. \& Bader, H. ,1990).

In 2004, peter Mahaffy has studied results of poster match, held by IUPC s' Committee on chemistry Education $\left(\mathrm{CCE}^{\dagger}\right)$ and with participation of $\mathrm{SAW}^{\ddagger}$. Five concrete examples of what tetrahedral chemistry education might look like:

- Chemistry Fuelling Modern Life

- Chemistry of our Planetary Support System

- Chemist-Creators

- Seeing and Understanding the Chemical World

- Chemistry of Life

According to his result, in addition to microscopic, macroscopic and symbolic dimensions which are considered in traditional education, human texture as fourth dimension should be taken into account at chemical education (Avi Hofstein, 2004).

\section{Method}

In this research, after encouraging students, It was asked them to paint their imagination about application of chemical concepts and its effect in society. Students participated in this research were 14-15 years old. They were selected from first grade student of Tehran (Capital of Iran) and Shahr-e Kord high schools. In the first grade high school chemistry course, Iranian students become familiar with some basic concepts and their application in life. These subjects are presented as a "Chemistry for Life" book with following chapters:

- Water, life source

- Following fresh air

- Again consumption, last continuation way

- Black gold, end of saving

Selection of painting subject was free for students. 45 paintings were collected from 75 persons in three classes and then were analyzed.

\footnotetext{
$\dagger$-IUPAC's Committee on Chemistry Education

+ - Science Across the World
} 


\section{Results}

Our results showed, the paintings could classify under four attitudes:

1.Misconception

2.Students scientific understanding of taught subjects

3.Life environment effect on painting subject selection

4.Effect of chemistry in life and society

\section{1. Misconception}

Students arrive in every new class-indeed, every new lesson-with their own notions of "how things work." Theorists and researchers refer to these notions by many terms-alternative frameworks, naive conceptions, alternative conceptions. We will call them misconceptions, and of all the things we can never be sure of in today's classroom, we can rely on the presence of student misconceptions in abundance. Sometimes misconceptions are formed from a student's past experiences, sometimes from incorrect past teaching; often the cause can't be identified. Theory tells us-and it is borne out in the evidence from the studies we've analyzed-that in the absence of complete and accurate schema, students will inductively assemble the various pieces they have in whatever whole conception seems to fit all of the data at hand. Regardless of the cause, there are strategies we can use to address and correct these misconceptions.

However, understanding historical events as a story or performing short theatre by students, has deep and permanent effect on learners learning, painting can be used to make chemistry learning attractive and help us to identify students misunderstandings. Students know chemistry as a science that deals with abstract and invisible concepts like mole, atom, chemical bond and etc; when they paint their imaginations and make relation between chemistry and art, they find chemistry interesting. In fact, they understand that chemistry and other science can be learned through other methods except texts, tables and graphs.

As shown in Figure 1, that was drawn by Razieh, 15 years old, we can see that she has understood CFC role in Ozone layer demolition, but she has no attention to make bond between oxygen atoms for presentation ozone molecules correctly. It means that she could not indicate triatomic molecules in her picture. But Atra (14 years old) indicates Ozone triatomic molecules and distance between them, also, she has considered energy of ultraviolet rays that breaks covalent bonds in Ozon molecules and infrared rays will be produced as a result (Figure 2).

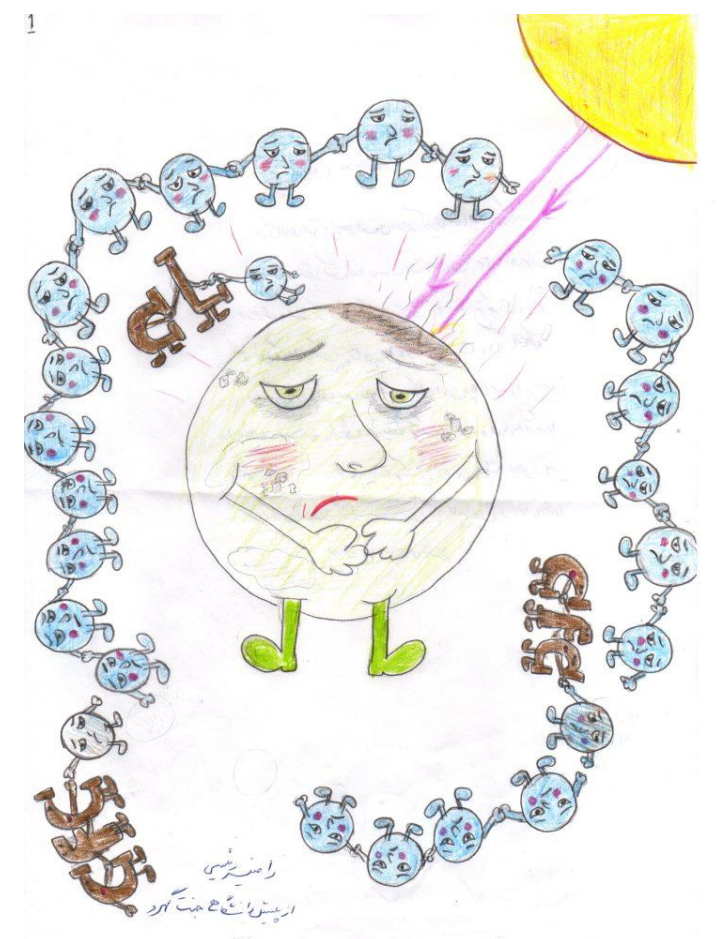

Figure 1. Razie has shown CFC role in Ozone layer demolition but she has taken into consideration ozone as continuity matter.

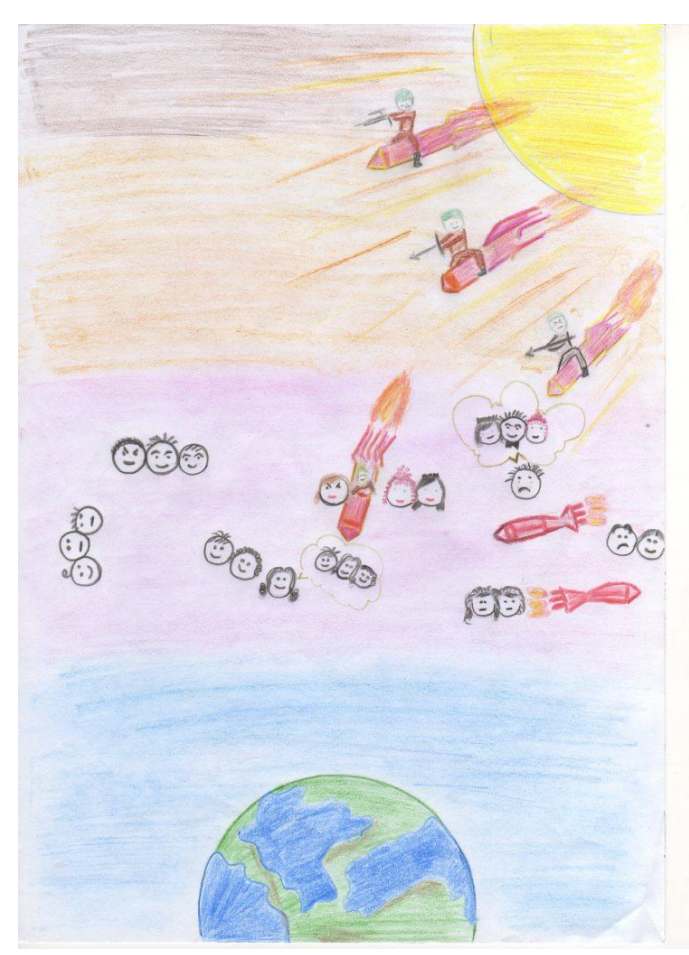

Figure 2. Atra supportive role of Ozone layer effect 
In Figure 3, we can see Fateme's painting (14 years old), it is based on chemical reaction between sodium and chlorine. She has presented energy liberation, heat and light in her painting correctly. But this student could not draw ionic bond in her picture. Also one of students, named Sahel, has indicated ionic bonds between sodium and chlorine as a family analogy in her painting (figure 4). Although they were from two different cities, however, they have indicated chemical bond in the same way as a human feature. Sahel has a perfect attention to neutralizing initial atoms, formation of ions after reaction and changing of atoms volume. Since she doesn't have any information about electronic configuration, and atomic structure, she could not indicate valance electrons correctly.

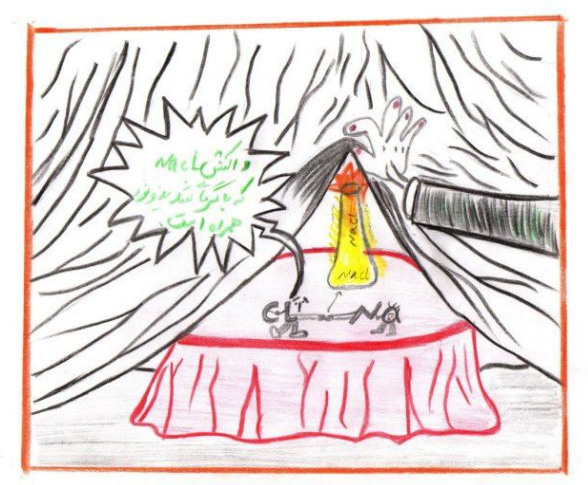

Figure 3. Fatemeh chemical reaction between sodium and chlorine

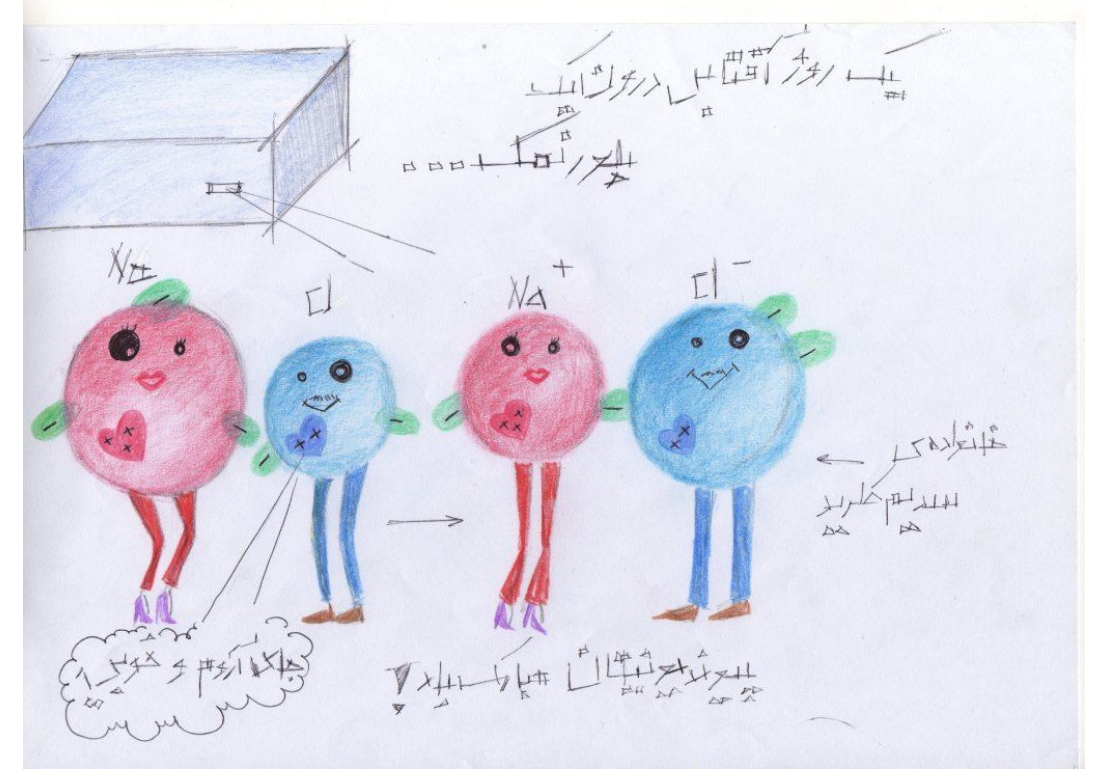

Figure 4. Sahel has shown sodium chloride as a family

\subsection{Students scientific understanding of taught subjects}

Students drew a scientific subject in most of the paintings. Some of them indicated scientific phenomena like energetic or number of atoms. According to paintings of students, teacher can evaluate their learning and modify misunderstanding objects. For example, teacher can help student's learning by showing the best paintings to students as you can see one of them in figure 3.

Samira has indicated ultraviolet (UV) and infrared (IR) rays with angry and kind face and triatomic of ozone molecule and diatomic property of Oxygen pointed out with appropriate numbers of faces (Figure 5). 


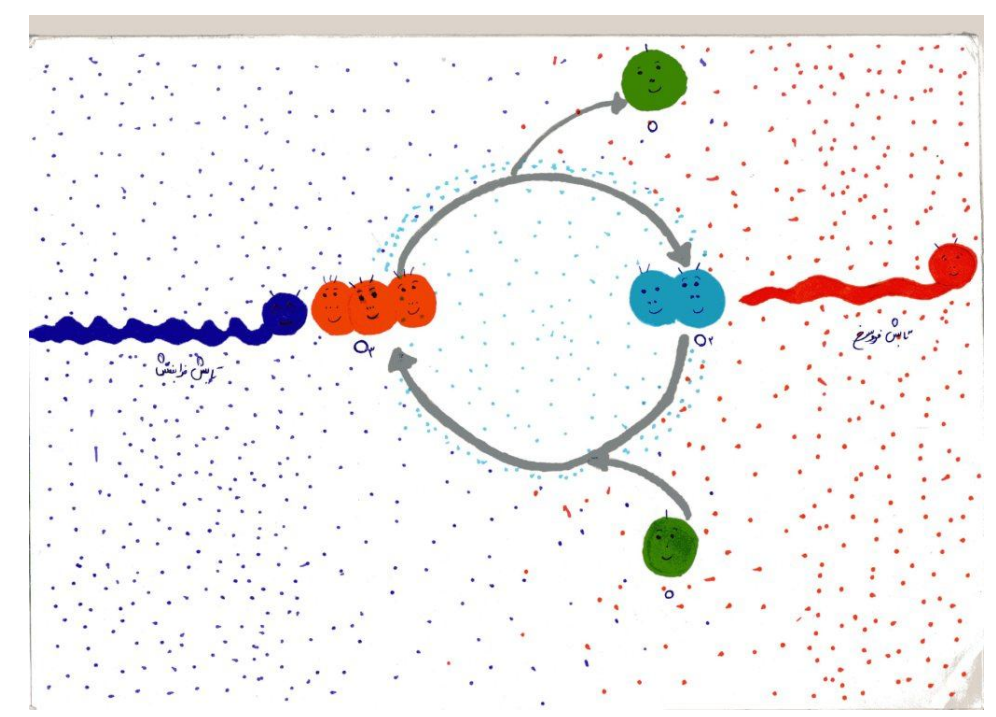

Figure 5. From view point of Samira, infrared (IR) rays have kind face because they have low energy

Elnaz, 14 years old, has drawn water circle in her painting (fig 6.). This student has emphasized important points like motion of water molecules in liquid form and Hydrogen bonds between them. Also, she has used particle property of material in her painting; therefore she has drawn water molecules with randomly movement separately and hexagonal structure of ice and endothermic vaporization process in her picture. However, she could not paint hydrogen bonding between water molecules correctly.

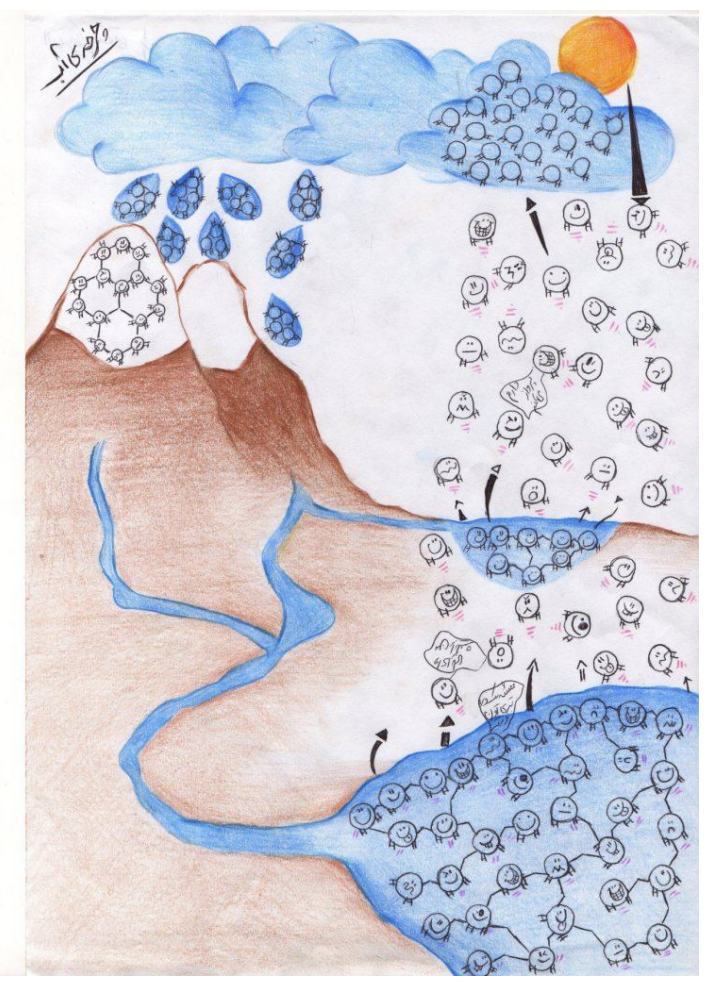

Figure 6. Elnaz's Painting and water cycle

15 years old Nahid, has pointed to free movement of molecules in liquid state and their agglomeration in solid state (Figure 7-1). She believes "When I heard about chemical lab, this picture comes to my mind about it". As shown in figure 7-2, you can see her imagination about chemistry laboratory. It was arisen from her less participation in laboratory or her findings about chemical materials hazardous probably. 


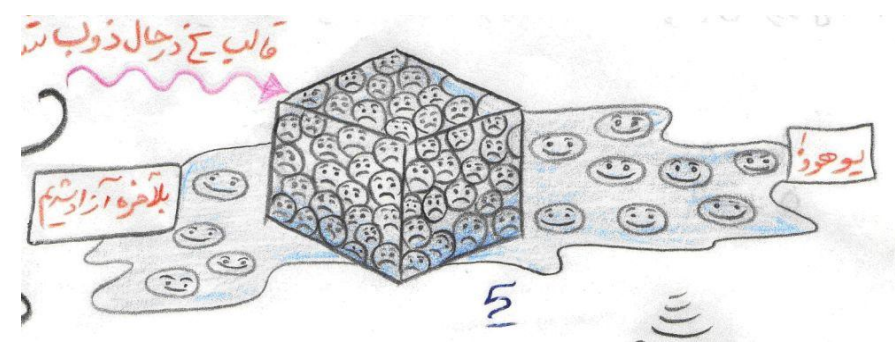

Figure 7-1. Nahid in her painting shows an ice that is melting and then molecules get freedom.

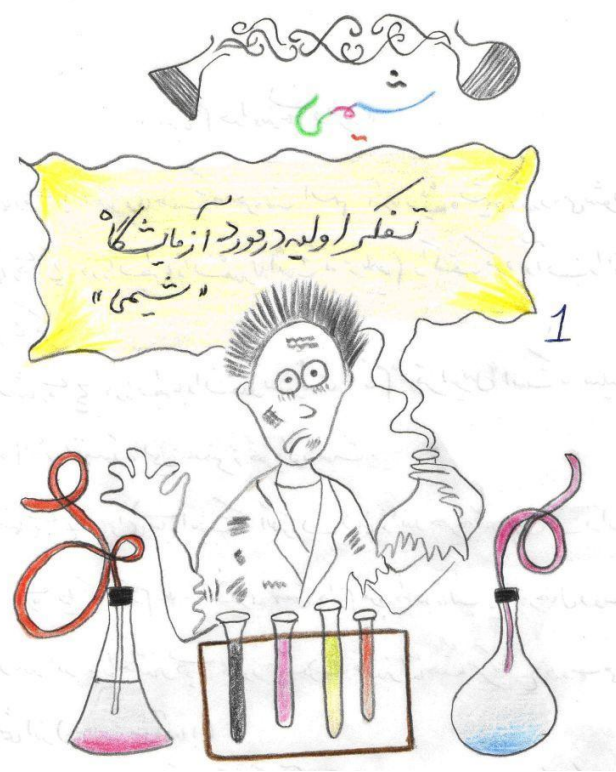

Figure 7-2. Nahid imagination from chemistry lab

Yasaman has drawn covalent bonding for atoms (Figure 8) and announced her opinions about painting effect on learning, she said:

These pictures are so wonderful and help us to understand covalent bonding topic.

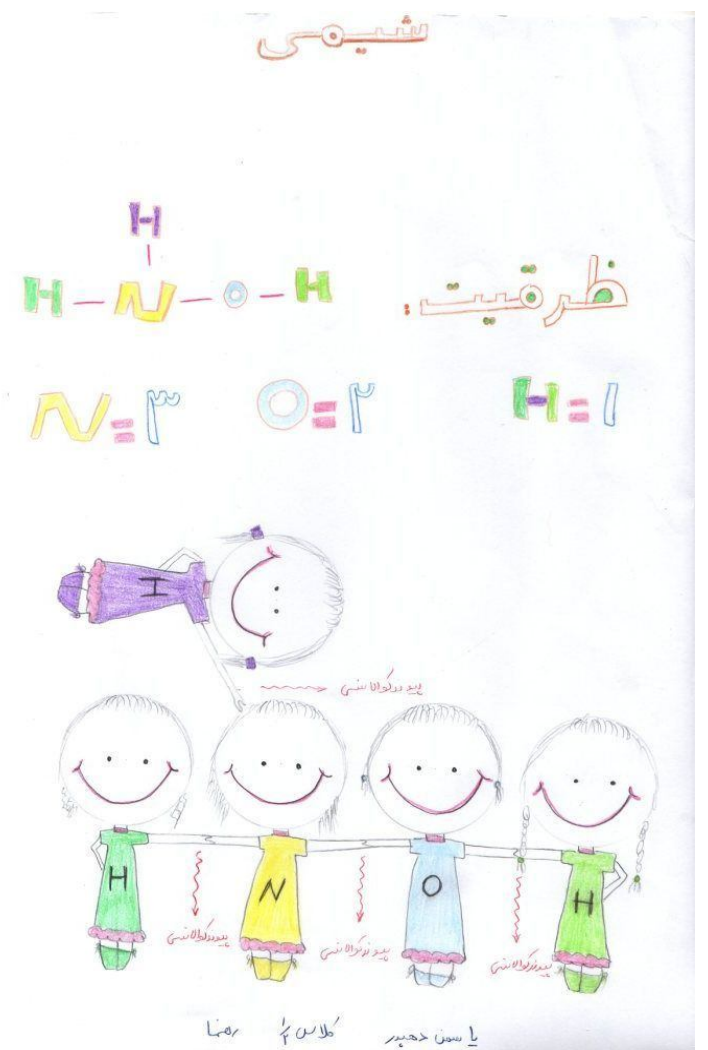

Figure 8. Humanistic personality for atoms in forming covalent bonding from opinion of Yasaman 


\subsection{Effect of chemistry in life and society}

One of the purposes of secondary course planning for chemistry teaching in Iran, is awareness of some chemical effects in daily life and chemical productions resulted from industrial activities on human and environment and familiarity of them with immunity points and environment support. Some of the students showed these subjects in their paintings.

Nazanin (14 years old) speaks about important effect of acid on the life. She explains that:

"Most of the people think that acid is a dangerous material, however this imagination is correct, if acid does not exist, some problems will be clear for scientific researches, environment and society!( Figure 9 )

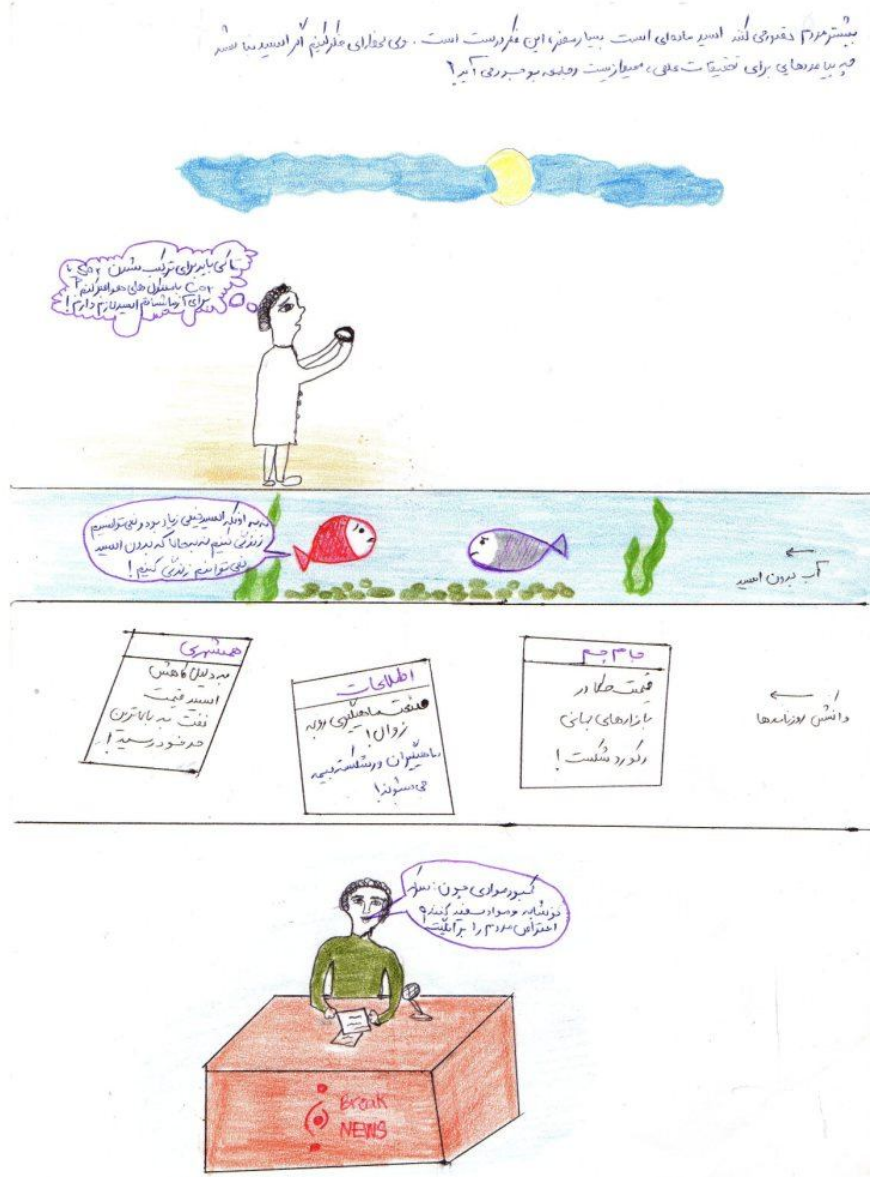

Figure 9. From view of Nazanin, acids are important for science researches and affect on social security

Considering this painting, it is clear that although textbook speak about non- desirable effects of acid rain, but students paid attention to positive effect of chemical materials like acids.

As shown in Figure 10, Shania has pointed to the quality of rain production and its effect on marine animals' environment. Also she uses $\mathrm{pH}$ as a device to determine water acidity and shows damages resulted from low $\mathrm{pH}$. Samare and Sadaf selected acid as a subject of their painting; they indicated bad effects of acid rain on living beings and also factors of making acid rains (Figure 11 and 12). 


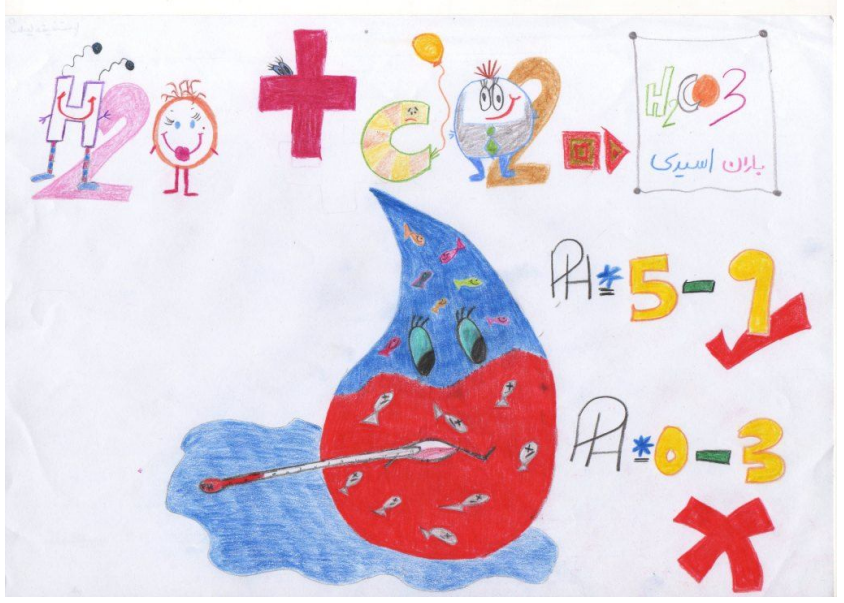

Fig.10. Shania and effects of acid rain on marine beings
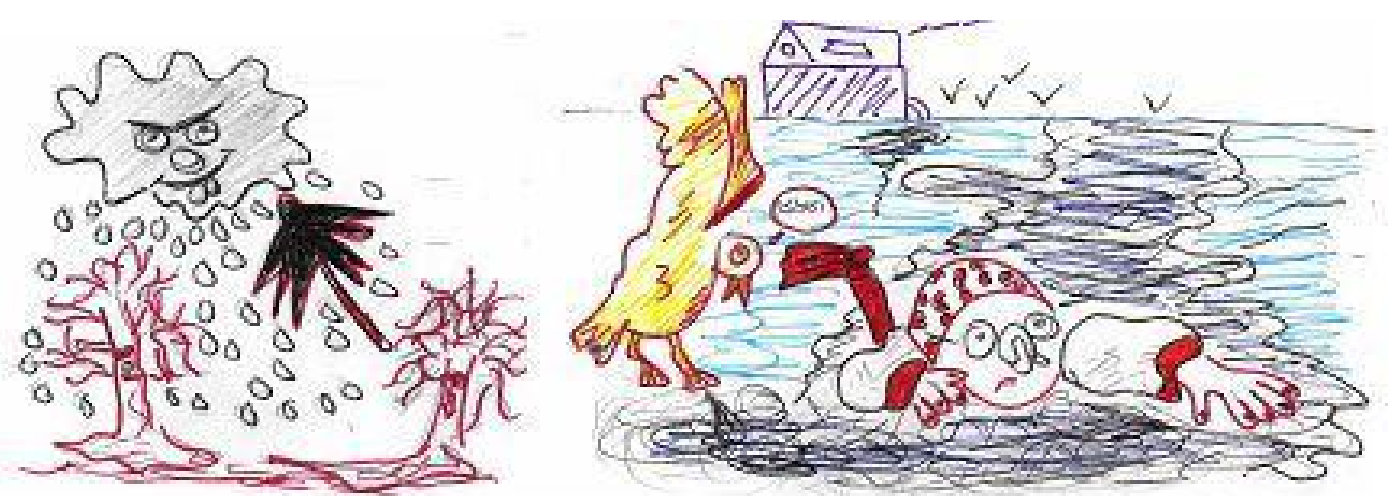

Figure 11. Sadaf has shown effects of acid rain on trees and environment

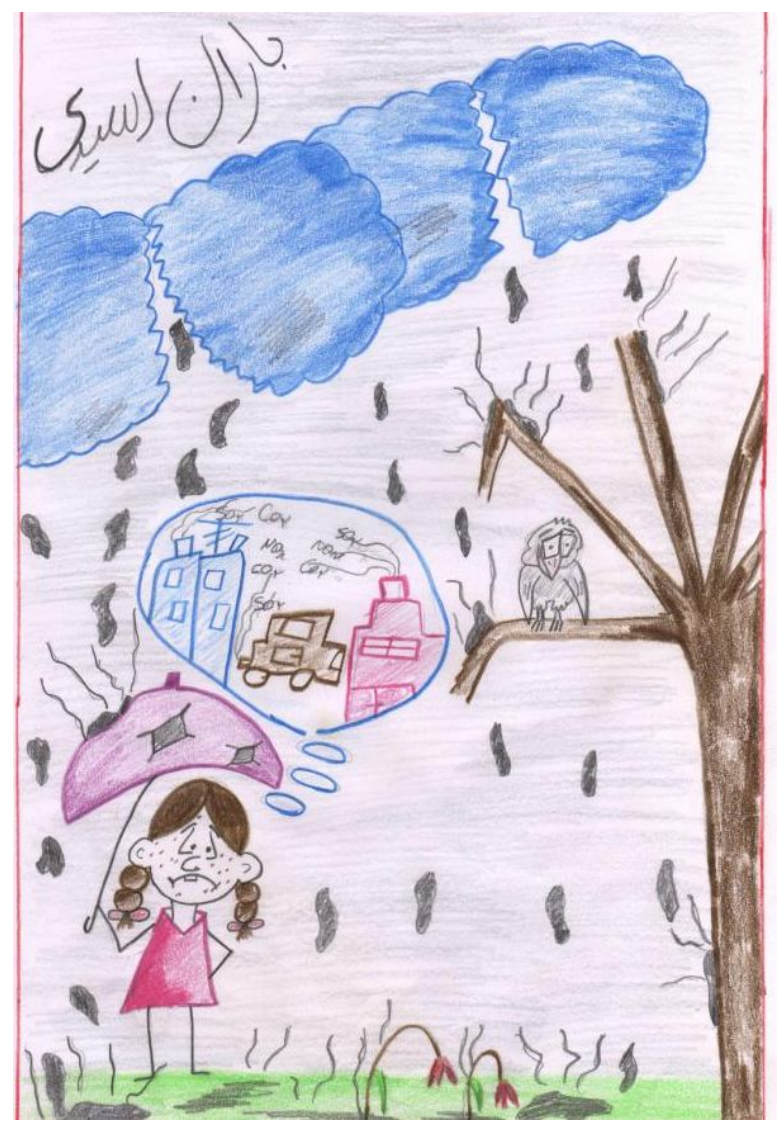

Figure12. Samare and effects of acid rain on living beings and also factors of making acid rains.

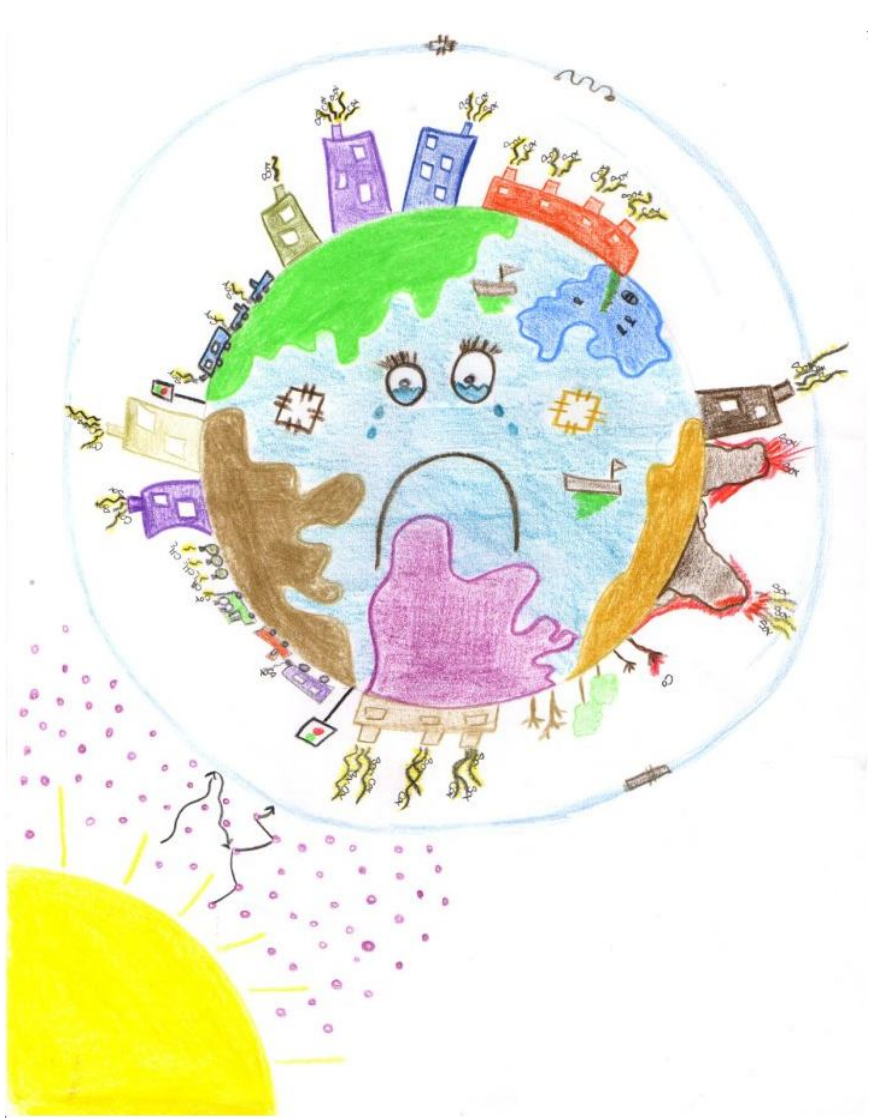

Figure 13. Yasaman has drawn earth and pollutants and their sources. 


\subsection{Effect of life environment on painting subject}

Referring to the collection of paintings, we can conclude that students of Tehran city that face air pollution and social difficulties in their city, indicate this subject in their paintings well, e.g. paintings of Shadan, Parastoo, Samareh, Sadaf and Yasaman (FIGURE 13). But students of Shahr- e Kord as a mountainous city paid attention to above mentioned subjects less.

\section{Discussion}

In Pictography, students can show what they have understood of chemical concepts. They use their intelligence, creativity and imagination to express learned concepts of chemistry. The created pictures by students indicate parts of scientific gap in their minds and hide misconceptions and their understanding of chemical concepts. By showing these pictures in the class, we can discuss about other learners thoughts to assay and criticize paintings. When groups of students discuss about pictures separately, teacher understands what they have learned and can modify educational problems and misconceptions.

One of the purposes of educational program is making an insight into relation between different branches of sciences. Another purposes of education in different societies are relation between chemical materials and natural resources, their effects on society and environment, application of this materials in life, technology role in appropriate materials expanding and decreasing bad effects of these materials. Inspection of student's paintings in the class, with group discussions, causes students responsibility about environment as a fourth aspect of chemistry education that was pointed by Mahaffy. The students as effective persons in the future should have correct view point about chemistry of materials and their effects that make correct decision about subjects of global society like energy, pollution and water.

One of the students pointed to this aspect of pictography (Figure 11):

Samare: I love painting, now that I draw a scientific subject, I should say that I understand acid rain better and I understand some other things, such as: damages arisen from acid rain in the future, and diagnosis different solutions. In my opinion, painting about scientific subjects is one of the best strategies for learning.

Macroscopic examples are mostly used for better understanding course materials, and students know about small particles like atoms, molecules and ions limitedly. Students with making some pictures about learned subjects, can understand these particles better and will be interested in chemistry.

This research is not just about student's insight into chemistry but it is studying their scientific learning and understanding of learned concepts. The interesting point, is the effectiveness of educational aspect of this method.

If teachers get more familiar with educational methods and types of educational evaluation, not only they are successful in education but also it makes desirable insight into students respect to chemistry especially in abstract and mental concepts. For example:

Parmis: Painting about chemistry is so pleasurable for me, and it helps to my learning and makes it Permanent in my mind.

Niloofar: Painting this picture, I can understand the subject completely and makes me better insight into different subjects in the chemistry book.

Shadan: When I was drawing this picture about bad weather, I remember Tehran, that people like me have to suffer from this weather.

Using mental pictures of students, increases learning depth especially at the conditions; we can not use laboratory, computer software, internet and etc for chemistry education. This method gives a chance to students to express their feelings about scientific concepts in their language and express their personal interpretation:

Neda and Negar: one of the effects of painting is that, we can understand the lesson better and learning becomes more simple. We can know our life environment. 
Parastoo: This picture (relation between water and air pollution) has many effects on learning chapter 1 and 2 of course book.

Atra: I understand my weak points about the learning of chemistry subject, I think that it will be desirable if we could paint all lessons of chemistry.

Maryam: After drawing about atmosphere, I could get familiar with pollution and memorized them like a film. This method has positive effect on me and I found that I learned and I will.

This method makes a new opportunity for students to express their experiences and opinions by a picture and use their learned subjects in new situations. Although, performing this experience need more time, it can be used at any time and about any subject in chemistry.

\section{References}

Avi Hofstein (2004). The laboratory in Chemistry Education, Thirty years of experience with developments, implementation, and research, Chemistry Education Research and Practice, vol. 5, no. 3, pp. 229-245

Claus Hilbing and Hans-Dieter (2000). Barke an Idea of Science: Attitudes towards chemistry and chemical education expressed by artistic paintings, Chemistry Education Research and Practice in Europe, vol. 1, no. 3, pp. 365-374

Wenck, H., Müller-Harbich, G., Bader, H. (1990). Die Einstellung von Realschülern zum:Chemieunterricht, zu Umweltproblemen und zur Chemie. chimica didactica, 16, 233-253.

Zafra M. Lerman (2001). Visualizing the Chemical Bond, Chemical Education International, vol. 2, Issue 1, 6-13 